\title{
English Teaching Reform in Local Undergraduate Colleges Based on Interlanguage Fossilization
}

\author{
Qin Yang \\ Faculty of Foreign Languages, Huaiyin Institution of Technology, Huai'an, China \\ Yujie Xu \\ Faculty of Foreign Languages, Huaiyin Institution of Technology, Huai'an, China
}

\begin{abstract}
The interlanguage fossilization is a distinguishing characteristic of second language acquisition and plays an important role in promoting the foreign language teaching in China. According to survey four main problems of English teaching in local undergraduate colleges have been found, involving language environment, teaching methods, teacher-student relationship and test mode. Therefore, this paper expounds the characteristics, classification and basic causes of interlanguage petrochemical phenomena, and proposes the main measures of English teaching reform in local undergraduate colleges from the perspective of theory of interlanguage fossilization. The reform measures are as follows (a)foster a good language learning environment, (b) emphasize learning strategy in the teaching process, (c) innovate teaching concepts and teaching models,(d) select high-quality teaching materials and strengthen teacher promotion.
\end{abstract}

Index Terms - interlanguage fossilization, local undergraduate colleges, English teaching, reforming measures

\section{INTRODUCTION}

Interlanguage was pioneered by American linguist Selinker who firstly proposed this concept at the 1969's Cambridge International Conference and formally used the term "Interlanguage" in his article in 1972.Selinker made it clear that interlanguage is a unique and independent linguistic system in which the second language learners recognize the manner and result of the target language in a particular stage of the learning process. Dai made a further generalization of this linguistic phenomenon, pointing out that interlanguage is a language system used by learners in foreign language learning between mother language and target language, and it has both language characteristics, and gradually closes to the target language, but not the exact target language(Dai,2001,2005).

Three main characteristics of interlanguage are summed up, namely systematic, permeable and dynamic. (1) Systematic. Although interlanguage is changable, the learners' use of second language is regular and predictable. Second-language learners, just like native speakers, use their known rules system to conduct communication, which is the concept of interlanguage comes from. According to its internal organization, it is also a system composed of internal elements, namely the rules system of speech, vocabulary and grammar. When it comes to its function, interlanguage can be used as a tool for interpersonal communication. (2) Permeability. Interlanguage is an open system which determines its permeability. Although interlanguage is developed step by step, it is not fixed at a certain stage. As the learner's language level improves and new knowledge permeates the original knowledge, the errors in the interlanguage are constantly revised to establish new language rules. This permeableness of interlanguage provides possibility of approaching target language. (3). Dynamicity that is named variability in other words, is one of the most prominent features of interlanguage. Like other natural languages, interlanguage is constantly developing and evolving, but changes are also in stages, and each stage is linked to each other to form a continuum. Each stage can be represented by a point on the continuum.

Numerous studies have shown that most learners' interlanguage will stay somewhere after reaching a certain level, instead of continuing to steadily move toward the target language as in the past. Some forms of non-target language will never disappear, and the so-called petrification phenomenon of interlanguage appears(Slinker,1992a). The researches on petrochemical phenomena by scholars at home and abroad mostly discuss the reasons for its formation in theory. After analyzing the relevant research results, this paper discusses how to help students in local undergraduate colleges overcome the rigidity in English learning, reduce the phenomenon of language petrification in English teaching, and help improve the efficiency of teaching and learning English.

\section{INTERLANGUAGE FoSSILIZATION}

\section{A. Definition of Fossilization Phenomenon}

Only about $5 \%$ of second language learners may eventually reach the level of the target language, that is, most of second language learners' interlanguage can't reach the end of their continuum. Selinker called the phenomenon as 
fossilization. Selinker explain the phenomenon of language fossilization refers to the fact that some linguistic items, grammatical rules and systematic knowledge in interlanguage of foreign language learners tend to be fixed, which age and the amount of study change do not work on. Fossilization structures generally exist in a latent manner or in the use of interlanguage even after apparently cleared up(Slinker,1992b).

\section{B. Classification of Fossilization Phenomenon}

The phenomenon of fossilization is divided into individual fossilization and group fossilization(Slinker,2001). And the individual fossilization phenomenon of learners manifests itself in the following aspects: (1) mistakes fossilization, (2) language ability fossilization. Mistakes fossilization appears as mistakes repeatedly appear after being corrected for many times and thought to have been cleared; the language ability fossilization refers to the interlanguage fossilization in speaking, grammatical structure and vocabulary. Group fossilization refers to the fact that when fossilized foreign language ability is universal and becomes a normal phenomenon in society as a whole, which will lead to the emergence of a new dialect.

\section{Characteristics of Interlanguage Fossilization}

The two prominent features of interlanguage fossilization are permanency and repetitiveness. Permanence means that the wrong language forms of the target language made by the second language learners are not only persistent but also indefinite. Repeatability refers to the wrong language forms of the target language made by the second language learners are repeated regularly, and this repeated error can be eliminated.

\section{Causes of Fossilization Phenomenon}

According to direct or indirect researches on fossilization from all aspects and perspectives, a series of factors have been identified as the reasons leading to fossilization of interlanguage. Selinker (1972) summarized the causes of fossilization phenomena into five aspects: (1) Native language migration, which refers to the transfer of native language features to second language learning in the process of learning second language; (2) The over-generalization of the rules of target language means that the learners use the individual language rules in the target language as the universal rules to create an interlanguage that does not have feature of the native language nor the target language; (3) Training migration means migration caused by the selection of teaching materials in which some language expression is not enough native or a bit difficult, the teachers' incorrect or inaccurate expressions, improper teaching methods or other factors; (4) Learning strategies refer to methods and strategies learners use in learning a second language or a foreign language. And their excessive analogy or simplification will form an interlanguage mistake in learning process; (5) Communicative strategies refer to a set of skills the learners use when encountering difficulties in the communication process. When learners can't express themselves in the correct target language, they will borrow the synonym, approximate expression consciously or unconsciously to form an intermediary language. Avoidance, retell, borrow, coinage are the commonly used communication strategies.

Schuman (1974) focuses on the impact of social and cultural environment on learners' psychology. His main theory is the cultural migration model. Schuman pointed out that if the cultures are quite different between society and target language of the L2 learners, it will cause some students' psychological burden so that they would be worried and try to keep a certain psychological distance with target language, and even reject to learn. In this way, the input of the target language will be limited, and the learner will rely on the mother tongue and the imperfect interlanguage, thus causing the petrification of the interlanguage. Schuman's actually admits the indivisibility of language and culture.

ELLIS (1994) analyzes the internal and external factors of interlanguage petrology from the perspective of biology and the motivation of learners. The internal factors emphasize that learners do not try to accept the cultural model of the target language because of the lack of cultural integration desire. The external factors mainly refer to communicative pressure and its feedback. The pressure is often felt when the learner exceeds his or her linguistic ability when learner wants to express in communication. And the long-term pressure often leads to language petrification.

Communicative feedback includes emotional feedback and cognitive feedback. The interlanguage used by the second language learner in the learning process will receive different emotional feedback and cognitive feedback from the native speaker or the second language teacher. Emotional feedback is transmitted by facial expressions, tones or gestures. There are three situations: positive, neutral and negative. Cognitive feedback is achieved through linguistic forms and there are also the same situations. If learners get positive emotional and cognitive feedback by using inaccurate or unfair language in the communication process, which will encourage learners to repeatedly use and form petrification in the long term. Therefore, it is best to use positive emotional feedback and negative cognitive feedback to avoid false petrification.

Long (2008) divides these factors into two major categories of internal and external factors as a whole, and the internal factors include cognitive factors, neurophysiologic factors and social emotional factors.

\section{Current Situation of English Teaching in Local Colleges And Universities}

"College English Curriculum Teaching Requirements" clearly puts forward that one of goals of college English teaching is to develop students' English comprehensive ability, especially listening and speaking ability, so that they can use English effectively in the future work and social communication in speaking and writing, while the other one is to 
enhance their ability to learn independently and improve their comprehensive cultural quality, so that they can meet the needs of China's economic development and international exchange. The overall level of college English teaching has made great progress, and the achievements are obvious. However, although many students spend more than half of their time studying foreign languages, they are still "passive" in the learning process. Because of the passive and ineffective learning process, some phenomena eventually formed, such as deaf and dumb English, "high score and low energy".This phenomenon is even more prevalent, especially in local science and engineering colleges.

According to the research results of relevant domestic experts and the author's teaching experience(Zhao X,2006;Bai ,2007;Tian,2008;Luo,2009;Yang ,2011), the teaching feeble in current local undergraduate English are summed up as follows.

\section{A. Lack of English Learning Language Environment}

Most Chinese students who are native speakers of Chinese are completely immersed in the environment of pure Chinese. The "Chi English" is the interlanguage fossilization caused by the mother tongue migration. In our country, except for a few English lessons per week, students rarely can talk in English at any other time. Moreover, except for large and medium-sized cities, most of our students usually start formal English learning in junior middle schools, At a result, their mother tongue have been basically shaped before English learning. Therefore, in the process of foreign language learning, especially in the formation of linguistic thinking, the mother tongue will undoubtedly have an impact on the study abroad.

\section{B. Relatively Lagging Teaching Philosophy, Teaching a Single Mode of Teaching Tools Behind}

According to a questionnaire survey conducted by China Foreign Language Education Research Center, English teachers in colleges still followed the traditional educational philosophy. In most of time teachers played the role of controllers and examiners in the classroom, neglecting the practicality of language teaching. Students lack initiative and selectivity in teaching, is not conducive to the enthusiasm of students. With the development of education, the studentcentered and student-centered teaching mode has become a trend. The role of teacher role should be changed to provide information, material support and topic guidance.

At the same time, due to lack of sufficient financial resources and material resources in some local undergraduate colleges, the allocation of teaching resources such as campus network teaching platform has yet to be improved, affecting the students' English application skills and teachers' teaching level.

\section{Imbalance between Teachers and Students, Teachers Need to Improve the Quality}

At present, the teaching tasks of public English teachers are arduous. Especially in underdeveloped areas, the underenrollment of college English teachers is widespread, the imbalance between teachers and students, the overload of English teachers and the limited opportunities for face-to-face exchanges with individual students. At the same time, college English teachers in local universities have fewer opportunities to go abroad for further study and exchange due to financial problems. They lack the chance to experience the language and cultural atmosphere of English-speaking countries immersibly. High-quality and highly qualified teachers' teams are difficult to form. The severity of linguistic and petrochemical phenomena may arise from the source of teaching.

\section{Students' Self-learning Ability Is Poor, and the Test-oriented Teaching Tends to Be Common}

According to the author's investigation, when students enroll in local undergraduate colleges, their skills of listening, speaking, reading, writing and translating are uneven. And the scores of CET 4 and CET 6 are indexed to the Bachelor Degree and the scholarship in many colleges, which makes the college English learning become benefit-driven. The college English teaching becomes "test-oriented education" which aims at researching tests, is taught for the tests and learnt for tests. In the end, the students' ability to use English is missing.

\section{IMPLICATIONS OF THE INTERLANGUAGE FOSSILIZATION ON ENGLISH TEACHING IN LOCAL COLLEGES AND} UNIVERSITIES

In 2017, there were 7.95 million undergraduate students in total in China, at least half of whom were enrolled in local undergraduate colleges. According to the investigation and analysis above, there are still many shortcomings in English teaching in local colleges in China. Interlanguage is an important part of the second language acquisition theory system. It reveals the psychological cognition process of second language learners, and involves important concepts such as language transfer, learning strategies and communication strategies. It can work on our English teaching and learning with the theoretical analysis of the petrochemical phenomenon of interlanguage. And also, through the analysis of the complex linguistic, psychological and socio-cultural factors that cause the interlanguage petrification, we realize that language errors are not completely negative factors, but an inevitable natural phenomenon. The repetitive nature of the interlanguage petrification tells us that the key is how to minimize the petrification of the interlanguage in the teaching practice.

\section{A. Develop a Good Language Learning Environment}

Second language acquisition is accomplished through language input. The main task of teaching is to provide the best 
language input for foreign language learners. Of course, this target input must be of high quality, diverse, and difficult. As mentioned above, when the social culture of the target language differs greatly from culture of mother tongue, the students will be psychologically alienated from language and lose interest and motivation of learning. The conducivation of ideal environment is an urgent task for college English teaching.

First of all, teachers should use pure English as the teaching language to the maximum extent in the process of classroom teaching. Advanced schools can also listen to and teach directly on the Internet. Secondly, colleges should create an atmosphere of extra-curricular English learning such as seminars and evening parties, English corner, English speech contest, English proficiency contest and composition contest, English radio programs, literary reading and appreciation, English short drama show, English short film and video.

Furthermore, introduction of various knowledge in social and cultural fields of English-speaking countries is particularly important. It is emphasized that the popularity of cultural knowledge is as important as linguistic knowledge while teaching. Only by understanding the culture carried by English language can students gradually accept and produce the desire to integrate with them, and also mobilize the motivation and interest of learning. The cultivation of cultural acquisition can also improve the pragmatic competence of learners and gradually transform their interlanguage into the target language. In addition to the traditional listening, speaking, reading and writing classes, it is also necessary to offer western film and television appreciation, western social etiquette, customs, literature, history, and religious electives.

\section{B. Emphasize Learning Strategy in the Teaching Process}

The phenomenon of petrification caused by learning strategies is one of the most common phenomena among learners. A large number of empirical studies show that the learning strategy is enlightened. The research on learner strategy can inspire and guide the actual foreign language teaching and learner learning process. In local undergraduate colleges, students with middle and low scores in English occupy a large proportion, so it is necessary to guide learning strategies and training into the teaching process. Based on the trichotomy strategy, the students of with poor basic skills should be given special guidance and training of metacognitive strategies, so that they can play a better role in the regulation and control of cognitive strategies. Meanwhile they should be encouraged and guided to use more vocabulary associations strategy and context strategy, and combined formal drills with the use of functional drills. Through the help of teachers in English learning process, a set of suitable learning methods can be summed up and make students the real change from passive to active interest in English learning.

In the realistic teaching, teachers should apply the comparative teaching method. Frist, they can compare the similarities and differences between English and Chinese in terms of pronunciation, vocabulary, grammar and discourse rules. Of course, teachers should correct the error petrification caused by learning strategies such as over-generalization and simplification. Second, they must compare Chinese and western cultures, and let students uderstand the differences between Chinese and English rules. After deepening their understanding of the mother tongue and the target language, students can better and consciously adopt active and effective learning strategies.

\section{Innovative Teaching Philosophy and Teaching Mode}

(1) Teachers should apply modern teaching concepts, establish appropriate teaching objectives and properly treat students' interlanguage errors. In order to reduce the communication pressure of students in the classroom, teachers should use positive emotional feedback to correct the mistakes caused by students' interlanguage, such as smiling and nodding. At the same time, teachers should pay attention to the use of the criticism words and do not hurt learning enthusiasm of students. According to the characteristics of petrochemicals, teachers should pay attention to two points when correcting mistakes. The first thing is the nature of the mistake should be noticed. The mistakes in understanding often indicate that the learner is ignorant of a certain language rule. The mistakes require corrected by teacher immediately. If not corrected, it will stay in the transitional language and produce petrification. The teacher should inform students of the correct usage and make it a new knowledge for the learner. This helps learners cultivate grammatical awareness. The second thing is some mistakes should be ignored. Generally speaking, the error in expression may be due to the difference between the two knowledge systems and capabilities. Learners often make mistakes, not due to ignorant of a rule, most likely because of an error in overusing their learning strategies. This kind of mistake often disappears after a while. This kind of error teacher can be ignored.

(2) There is a large individual difference in the English proficiency of students in local colleges and universities. As a result, we should fully recognized the differences. Implementing graded and hierarchical teaching is the solution to this problem. Teachers try to correct the mistakes made by beginners, which will improve their self-confidence in future studies. If the learner is in an advanced stage, these mistakes are often ingrained, and the teacher's correction will have little effect.

(3) Teaching mode can be changed based on modern information technology, especially the network technology and multimedia technology. These measures may break the limit in time and place of English teaching. Their focus is on personalized learning and active learning direction. Finally, modern information technology can makes English teaching more practical and happy. 
According to the theory of interlanguage fossilization, training and migration will lead to the phenomenon of petrification. Therefore, the ability of teachers and the theoretical level, as well as the selection of appropriate teaching materials, will have a direct impact on learning effectiveness.

In local colleges and universities, it is necessary to strengthen the training of English teachers. First, English teachers should been regularly assigned to famous universities in China to study and learn. Local undergraduate colleges should support English teachers to participate in short-term education, and encourage young teachers to pursue doctoral degrees in their fields, and actively conduct academic research with neighboring universities. Through professional seminars and teaching seminars, the knowledge category is expanded and the professional level of English teachers improve.

Local undergraduate colleges should also provide more opportunities for English teachers to go abroad. Teachers can go abroad for half a year to one year by applying for visiting scholars. They can be exposed to different teaching methods. They also be exposed to professional frontier trends. At the same time, local undergraduate colleges should invite famous foreign scholars to come to their school to give lectures, so that teachers who have no chance to study abroad can broaden their horizons and expand their thinking.

At the same time, referring to local undergraduate students' ability to learn and the actual level, the selection of appropriate English teaching materials is important. Teaching materials should be updated with the times, vivid and interesting. The structure of content should be reasonable to start and improve step by step. Of course, teaching materials must be authentic and contextualized. The information and meaning conveyed by these materials depend on the social context in which they are located and cannot be understood in isolation. The difficulty of the textbook should be moderate, and content should be consistent with the students' cognitive and thinking abilities. Textbooks that are above or below the student's abilities will undermine the student's motivation and interest. In addition, outdated textbooks of language and content should be abandoned. If the language textbooks cannot keep up with the development and changes of the society, it is difficult for students to obtain the target language materials in the true sense, and it is difficult to stimulate their interest in learning.

\section{CONCLUSION}

In recent years, with the expansion of the scale of running local undergraduate colleges in China, the number of students has increased, and English teaching has received more and more attention. However, there are four main problems in English teaching in local undergraduate colleges: the lack of language environment for English learning; the teaching philosophy is relatively lagging, the teaching mode is single, the teaching methods are backward; the teacher-student ratio is out of balance, the quality of teachers needs to be improved; Poor, the test-oriented teaching tends to be ubiquitous. This paper expounds the characteristics, classification and basic causes of interlanguage petrochemical phenomena, and proposes the main measures of English teaching reform in local undergraduate colleges based on the interlanguage petrochemical theory: (1) foster a good language learning environment,(2) Emphasize learning strategy in the teaching process,(3) Innovate teaching concepts and teaching models,(4) Select high-quality teaching materials and strengthen teacher construction.

In the future, English teachers in local undergraduate colleges can use the theory of interlanguage petrochemistry, combine the reality of English teaching with the characteristics of students' learning, apply new teaching modes, change teaching concepts, update teaching content, optimize curriculum settings, and improve English teaching. quality.

\section{ACKNOWLEDGMENTS}

This work was supported in part by a grant from Jiangsu social science plan funds project —— "Translation Ecosystem of Buzz Words" and Huaiyin Institute of Technology research project___ "On the Image Thinking of Chinese Translators in Literary Works from the Perspective of Translation Aesthetics". The authors wish to thank Huaiyin Institute of Technology to provide support.

\section{REFERENCES}

[1] Bai,F.X.(2007). A general review of the theoretical studies of interlanguage and fossilization in China. Journal of Hebei Normal Universit(Philosophy and Social Sciences Edition),30.4, 115-119.

[2] Dai,W. D. \& Cai, L. Q. (2001).SLA research in China: a survey, Foreign Languages and Their Teaching,149.9,2-5.

[3] Dai,W.D. \& Zhou,D.J. (2005). SLA research in China: s survey, Journal of Foreign Languages, 160. 6, 62-70.

[4] Ellis.R. (1994). The study of second language acquisition. Oxford: Oxford University Press.

[5] Gass,S.M. \& Selinker, L. (1992). Language Transfer in Language Learning. Netherlands: John Benjamins Publishing Company.

[6] Long,M.H. (2008). Stabilization and fossilization in interlanguage development. In Doughty,C.J. \& Long.M.H.(Eds.),The Handbook of Second Language Acquisition. Malden: Blackwell Publishing, 487-535.

[7] Luo,K.K. (2009). Enlightenment of petrified foreign language teaching in interlanguage. Journal of Inner Mongolia Agricultural University (Social Science Edition), 11.4,159-160.

[8] Schumann,J.H. (1974). The implications of interlanguage, pidginization and creolization for the study of adult second language acquisition. TESOL Quarterly, 8.2, 145-152.

[9] Selinker,L. (1972). Interlanguage. International Review of Applied Linguistics. 10,209 -231. 
[10] Selinker,L. (1992). Rediscovering interlanguage. New York: Taylor \& Francis.

[11] Selinker, L. \& Han, Z. (2001). Fossilization: Moving the concept into empirical longitudinal study. In Elder.C. \& Brown.A (Eds.), Studies in language testing: Experimenting with uncertainty (vol.27). Cambridge: Cambridge University Press, $276-291$.

[12] Tian,Z.H.\&Tian,Y.S. (2008). Analysis of the status quo of college english in local universities and countermeasures. Journal of Jilin Agricultural Science and Technology College. 17.4,105-107.

[13] Yang,L.\& Pan,Y. (2011). The enlightenment of interlanguage fossil concept on college english teaching. Journal of Southwest University for Nationalities (Humanities and Social Science), S2, 169-170.

[14] Zhao,X. (2006). Interpretation of interlanguage fossilization and interlanguage psychological cognitive mechanism.Foreign Languages and Teaching, 204.3, 18-20.

Qin Yang received her master's degree from Nanjing University, China in 2013. She is currently a lecturer in the Faculty of Foreign Languages, Huaiyin Institution of Technology, Huai'an, China. Her research interests include second language acquisition, translation and English teaching reform.

Yujie Xu received her master's degree at Nanjing University of Technology, China in 2014. She is a lecturer in the Faculty of Foreign Languages at Huaiyin Institute of Technology, Huai'an, China. Her research interests are translation methods and applications. 